\title{
Specificity of working memory mechanisms in individuals
}

\author{
Elena Nikolaeva*, Polina Ivashina, Evgeniy Berezhnoy, and Inna Kalabina \\ Herzen State Pedagogical University, 191186, Saint-Petersburg, Russia
}

\begin{abstract}
The research analyzes the capacity of working memory and the mechanisms which determine effectiveness of retrieval in people with longlasting (from 5 to 20 years) drug use history. The relevance of the research is supported by the fact that the working memory is considered to be a central mechanism of self-control, which, in turn, is considered a leading parameter when an indi-vidual chooses the path to addiction. The research studied 258 people, 151 of whom, $37.1 \pm 10.7$ years old, have never used substances, and the group of 107, 35.8 \pm 7.8 years old, who have long-lasting (from 5 to 20 years) drug use history. The working memory specifics were evaluated by O.Razumnikova's technique, which allows retrieval of the same set of stimuli presented in different consequence and in three series to be described. The research studied the most discussed mechanisms functioning in the working memory separately: retrieval-induced forgetting and retrieval-based learning. Our data suggest that the structure of the working memory mechanisms does not change along with long-lasting substance use while in case of the RBL effect the difference is threefold: in case of repeated retrieval, the addicts demon-strate insignificant improvement of memorization ability in comparison to the drug-free controls.
\end{abstract}

\section{Introduction}

There are numerous studies of the effect of the use of various drugs on a person's cognitive abilities and social activity. However, they are often carried out on very small samples [1], which significantly affects the result. In this case, the result can be determined by random events, sometimes completely unrelated to the very mechanism of dependence formation.

A meta-analysis of 44 studies that examined the effects of methamphetamine use in 1,592 subjects versus 1,820 non-drug users found several cognitive domains (including attention, executive functions, language / verbal fluency, verbal learning and memory), and the complete absence of changes in some psychological areas, for example, visual learning and visuo-spatial abilities [1]. Moreover, the most pronounced changes are found in the reinforcement system, which has been proven by many studies [for example, 2]. It is known that it is the reinforcement system that is responsible for the long-term maintenance of the desire to use certain substances [3].

The importance of studying the effect of drugs on the brain state is due to a heated discussion between researchers in this area. It is described in the work of N. Heather et al.

* Corresponding author: klemtina@yandex.ru 
[4]. There are researchers who insist that drugs change the structure and function of the brain [5], and there are those who believe that 'substance abuse cannot be divorced from its social, psychological, cultural, political, legal and environmental contexts: it is not simply a consequence of brain malfunction' [6, p. 40]. The first model for describing the formation of addiction is called the brain disease model of addiction, the last one is the Addiction Theory Network. The first model leads to stigmatization and marginalization of dependent people, their isolation from society. The second model assumes the possibility of full recovery of these people and participation in public life, subject to substantial support in the immediate environment. There are strong arguments in support of each of these models, which requires additional research.

How society treats addicts and how it will build preventive measures and provide assistance to those who already use drugs determine the severity of this debate. In the first case, it is necessary to treat the brain disease and isolate the person who is considered sick. In the second case, a person is considered within the framework of the circumstances that led him (her) to such behavior, and therefore a change in the social environment is required, perhaps a partial change in the country's legislation, etc.

To understand the real processes occurring in the brain and the reasons for the need to use drugs, further research is needed, which to one degree or another relate to the specifics of working memory in addicts.

\subsection{Working memory and its mechanisms}

Working memory (WM) is a memory, which makes it possible to remember all interim stages of carrying out a task [7]. From this point of view, it is working memory that allows a person to adhere to a chosen goal and refuse distracting stimuli and actions. WM is the central characteristic of self-control that allows a person to set their own goals and achieve them.

In WM, there are multidirectional mechanisms that ultimately determine the volume of memorized material. The most discussed mechanisms operating in WM are retrieval-induced forgetting (RIF) and retrieval-based learning (RBL) [8,9]. RIF means worsening of retrieval of subsequent stimuli as a result of retrieval of some preceding stimuli which are close to them by some parameter

There is no common understanding of the RIF mechanism. One of the mechanisms of worsening of retrieval is believed to be a proactive interference, that is, memories of the preceding stimuli overlap new information and weaken a new emerging memory trace [10].

There is an assumption [11] that forgetting does not happen due to competition of memory traces but can be explained by active inhibition process. There is a position [12], which combines both interference and special inhibition processes.

RBL is a process when every subsequent retrieval in working memory leads to better memorization of information when it is repeated [13].

Both processes [14] determine the result of testing the WM. Apparently, the RIF and RBL mechanisms are formed independently of each other and have different critical periods [15].

\subsection{Effects of addiction on memory processes}

There are several most accepted models explaining why an addiction develops: the affective processing model of negative reinforcement, the cognitive processing model, the incentive sensitization theory of addiction and the theory of neural opponent motivation. They all associate negative emotions and stress with memorizing the short way out of the situation occurred [16]. Some papers even consider WM as a possible predictor of addictive behavior $[17-21)$. This is explained by the important role of self-control in developing addictive behavior. It is believed that the WM is a central component of self-control [22]. 
Both self-control and WM are connected to the maturity of the prefrontal cortex. Deficit functioning of the prefrontal cortex is discovered in many types of addictive behavior [23]. At the same time, there is no data on what is primary and what is secondary in the formation of addiction. It can be assumed that the deficit in the functioning of the prefrontal cortex facilitates the entry into addiction. However, there is also the possibility that it is the dependence on active substances that leads to a slowdown in the maturation of the prefrontal cortex.

\subsection{Objective setting}

Ambivalence of available results does not make it possible to understand which working memory mechanism- RIF or RBL - is affected most in drug dependent individuals. Of particular interest are people who have been using drugs for a long time - more than 10 years. Duration means there is some control over substance use. It can be assumed that a decrease in the RBL efficiency will contribute to the possibility of manipulating the set goal, changing or distorting it. This will facilitate the authorization to use drugs at a specific point in time. However, data on the ratio of RIF and RBL in people with long-term drug use experience. This became the goal of this work.

\section{Materials and methods}

To evaluate the processes developing in the working memory, a technique [24] was used which allowed the researchers to study visual object memorization on a computer screen. The technique included three series, during which the same set of simple objects (30 units) was presented, but the order of presentation varied from series to series. Object selection time was not limited.

The subject's task was to select objects on the screen that had not been previously marked. As soon as the subject pressed on an object the presentation of stimuli stopped if subject had already selected it, and a new series began with the presentation of the same objects in a different order. The number of reproduced stimuli in each series was counted. RIF was determined when the subsequent recall was worse than the previous one. RBL was determined when the subsequent recall was better than the previous one.

The research studied 258 people. The first group includes 151 subjects, $37.1 \pm 10.7$ years old, have never used substances. All of them were volunteers. The second group includes 107 subjects, $35.8 \pm 7.8$ years old, who have long-lasting (from 5 to 20 years) drug use history. This group included both Alcoholics Anonymous and Narcotics Anonymous

All controls gave their voluntary consent to be examined and to have the data ob-tained processed. The ethical committee approved the study.

For statistical data processing, the IBM SPSS Ver.22 software package was used.

\section{Results and discussion}

First, the amount of working memory was estimated in three attempts.

Table 1. The capacity of the working memory in three attempts (number of correct answers, means and standard deviations)

\begin{tabular}{|l|l|l|l|}
\hline Groups & 1 attempt & 2 attempt & 3 attampt \\
\hline Addiction & $12.4 \pm 6.3$ & $9.0 \pm 5.2$ & $8.5 \pm 4.5$ \\
\hline Norm & $15.7 \pm 6.8^{*}$ & $10.8 \pm 5.7$ & $10.4 \pm 6.1^{*}$ \\
\hline
\end{tabular}


Note: ${ }^{*}$ - difference with a significance level of 0.05 between groups (Student t-criterion)

Table 1 shows that the WM capacity is bigger in drug-free controls in all attempts. At the same time, while the group of controls with addictive behavior demonstrate bigger decrease of memory in every subsequent attempt, the group of normal controls do not demonstrate any changes between the $2^{\text {nd }}$ and the $3^{\text {rd }}$ attempts. It allows an assumption to be made that the WM mechanisms may be different.

That is why RIF and RBL for each group continued to be analyzed (Table 2).

Table 2. Distribution of RIF and RBL in different groups (\%)

\begin{tabular}{|l|l|l|}
\hline Groups & RIF & RBL \\
\hline Addiction & 86.8 & 54.4 \\
\hline Norm & 84.3 & 53.0 \\
\hline
\end{tabular}

As Table 2 shows, the structure of the mechanisms remains unchanged but the differences are here: the normal increase of RBL capacity is 9.9 objects while in addicts it is 3.7. Consequently, the mechanism is the same but its range decreases by three times. Subjects with long-term experience of drug or alcohol use learn significantly worse during the reproduction process compared to those who do not have such experience.

After obtaining qualitative results, a regression analysis was conducted. The results of the regression analysis through the whole sample are presented in Table 3.

Table 3. Influence of the independent variable 'period of substance use' on dependent variables

\begin{tabular}{|l|l|l|l|}
\hline Dependent variables & $\boldsymbol{\beta}$ & $\mathbf{R}^{\mathbf{2}}$ & $\mathbf{p}$ \\
\hline Recall in the first attempt & -0.188 & 0.035 & 0.08 \\
\hline Recall in the third attempt & -0.153 & 0.023 & 0.032 \\
\hline RBL & -0.392 & 0.154 & 0.000 \\
\hline
\end{tabular}

The table shows that all dependent variables have negative coefficients of regres-sion. It is shown that the length of the period of substance use negatively correlates with the retrieval level in the 1st and 3rd attempts (the longer the period of substance use, the smaller the WM memory capacity). Then it correlates with the decreased RBL capacity in retrieval (the longer the period of substance use, the smaller the less the improvement in reproduction in the subsequent attempt compared to the previous one).

Many studies revealed changes of the working memory in people who use drugs [25]. We managed to demonstrate that the structure of the working memory mecha-nisms remains unchanged but improvement of retrieval significantly decreases in every subsequent retrieval. This leads to a decrease in the initial volume of working memory and its progressive decrease with each playback.

Therefore, our assumption that long-term drug use is due to impairment of learning mechanisms in WR was confirmed. It is worth emphasizing that over the course of 20 years, many of the subjects have undergone rehabilitation courses many times and vowed never to use drugs again. Nevertheless, each of these attempts to achieve the goal of not using drugs has failed. Perhaps it is the deterioration of learning that allows one to momentarily either slow down the process of movement towards the goal, or change the very direction of movement towards a different goal.

Earlier we talked about the presence of two models of the addictive behavior formation Brain Disease Model of addiction and Addiction Theory Network. Our data is more in line with the latest model. From this position, restoration of the effectiveness of training, for example, in the framework of behavioral therapy, can contribute to the successful release of addictive behavior. 


\section{Limitation}

Our study did not separate the groups of drug addicts anonymous and alcoholics anonimus. Perhaps the change in the effectiveness of the RBL mechanism will be slightly different in each group. Nevertheless, our subjects were united by the parameter of duration of drug use, which allows us to evaluate precisely the factor of no change in the effectiveness of rehabilitation measures.

\section{Conclusion}

Our data suggest that the structure of WM mechanisms does not change along with longlasting substance use history while the RBL effect value differs threefold: in case of repeated retrieval, the addicts (both alcoholics anonymous and narcotics anonymous) demonstrate insignificant decrease of memorization ability in comparison to the drug-free controls. At the same time, it is difficult to decide what comes first: whether decreased memorization capacity in WM retrieval increases probability of drug use or the drug use results in weakened improvement of retrieval in every subsequent retrieval instance.

Our data is more consistent with the Addiction Theory Network rather than the Brain Disease Model. From this position, restoration of the effectiveness of training, for example, in the framework of behavioral therapy, can contribute to the successful release of addictive behavior.

\section{References}

1. S., Potvin, J. Pelletier, S. Grot, C. Hébert, A.M. Barr, T. Lecomte, Addictive Behaviors 80, 154-160 (2018) doi.org/10.1016/j.addbeh.2018.01.021.

2. A.S. Dean, S.M. Groman, A.M. Morales, E.D. London, Neuropsychopharmacology 38(2), 259-274 (2013).

3. R.J. Rosenthal, S.B. Faris Addiction Research \& Theory 27(5), 437-449 (2019) doi.org/10.1080/16066359.2018.1543412

4. N. Heather, D. Best, A. Kawalek, M. Field, M. Lewis, F. Rotgers, R.W. Wiers, D. Heim, Addiction Research \& Theory 26(4), 249-255 (2018) doi: 10.1080/16066359.2017.1399659.

5. N.D. Volkow, G.F. Koob, A.T. McLellan, N Engl J Med. 374, 363-371 (2016) https://www.nejm.org/doi/10.1056/NEJMra1511480

6. D. Heim, Nature 507, 40 (2014)

7. R.G. Alloway, T.P. Alloway, Understanding working memory (2nd ed., Sage, Los Angeles, 2015) doi: 10.1017/edp.2015.14

8. C. Cinel, C.C. Mack, G. Ward, Journal of Experimental Psychology: General. 147(5), 632-661 (2018) http://dx.doi.org/10.1037/xge0000441.

9. O.M. Razumnikova, E.I. Nikolaeva, Questions of psychology 1, 123-129 (2001)

10. C.A. Rowland, L.E. Bates, E.L. DeLosh, Frontier in Psychol. 5, 1343 (2014) doi: 10.3389/fpsyg.2014.01343.

11. L. Postman, Interference theory revisited (In J. Brown (Ed.), Recall and recognition, New York, NY: Wiley., 1976)

12. M.C. Anderson, B.J. Levy, Psychology Press Publ. 107-132 (2010) 
13. K.A. Norman, E. L. Newman, \& G. Detre, Psychological Review 114, 887-953 (2007) doi:10.1037/0033-295X.114.4.887

14. V.S. Merenkova, O.E. Elnikova E.I. Nikolaeva, Science for Education Today 10 (6), $27-$ 39 (2020) https://www.elibrary.ru/item.asp?id=44478880. - DOI: 10.15293/26586762.2006.02.

15. O.M. Rasumnikova, E.I. Nikolaeva, Questions of psychology 2, 124-132 (2019) doi: 10.11621/pir.2018.0206.

16. H.J. van Lier, M.E. Pieterse, J.M.C. Schraagen, M.J. Postel, M.M. Vollenbroek-Hutten, H.A. de Haan, Addiction Research \& Theory 26 (1), 35-51 (2018) doi.org/10.1080/16066359.2017.1309525

17. J. Loughead, E. Wileyto, K. Ruparel, Neuropsychopharmacol 40, 1311-1320 (2015) doi.org/10.1038/npp.2014.318

18. A.M. Day, C.W. Kahler, J. Metrik, N.S. Spillane, J.W. Tidey, D.J. Rohsenow, Nicotine \& Tobacco Research 17( 9), 1173-1177 2015 doi.org/10.1093/ntr/ntu259

19. S. Lannoy, V. Dormal, J. Billieux, P. Maurage, Addiction Research \& Theory 27 (6), 498-506 (2019) doi.org/10.1080/16066359.2018.1549233

20. T.D. Wilcockson, E.M. Pothos, Addictive Behaviors 44, 88-93 (2015) doi.org/10.1016/j.addbeh.2014.12.015

21. M.W. Otto, F. Eastman, S. Lo, B.A. Hearon, W.K. Bickel, M. Zvolensky, Clinical Psychology Review 49, 67-78 (2019) doi.org/10.1016/j.cpr.2016.07.003.

22. K.D. Tahaney, T.P. Palfai, Addictive Behaviors 81, 46-49 2018 doi.org/10.1016/j.addbeh.2018.01.011

23. M. Lyvers, C. Czerczyk, A. Follent, Ph. Lodge, Addiction Research \& Theory 17(6), 668-677 (2009) doi.org/10.3109/16066350802404158

24. O.M. Rasumnikova, E.I. Nikolaeva, Questions of psychology 2, 124-132 (2019) doi: 10.11621/pir.2018.0206.

25. E.A. Oteva, E.I. Nikolaeva, A.A. Nikolaeva, V.N. Sartakova, Yu.N. Parm, Akusherstvo I ginekologia 70(3), 25-27 (1994) 